\title{
CONUT: A Useful Alarm of Malnutrition in the Centralized Laboratory of a Spanish Hospital
}

\author{
Miriam Menacho-Román ${ }^{1}$, Gilberto Pérez-López², José Manuel del Rey-Sánchez', Domingo Ly-Pen ${ }^{3 *}$, \\ Antonio Becerra-Fernández ${ }^{2}$
}

${ }^{1}$ Clinical Biochemistry Department. University Hospital "Ramón y Cajal", Madrid, Spain

2Endocrinology Department. University Hospital "Ramón y Cajal", Madrid, Spain

${ }^{3}$ Abbey House Medical Centre, Navan, Ireland

*Corresponding Author: Domingo Ly-Pen, Ph.D., Assistant Professor, Abbey House Medical Centre, Navan, Ireland. Tel: +353833502402, Email: domingoly@gmail.com

Received March 4, 2018; Accepted June 12, 2018; Online Published August 29, 2018

\begin{abstract}
Background: Hospital malnutrition, usually secondary to various diseases and their treatments, is an important problem in our clinical practice. For its proper assessment, it is crucial to use a nutritional alert system, such as the CONUT (COntrol NUTrition) program; this tool uses 3 analytical parameters: serum albumin, total cholesterol, and total lymphocyte count.

Objective: The current study assessed the results of the implementation of this program in the University Hospital Ramón y Cajal.

Methods: The CONUT program has been used in the University Hospital Ramón y Cajal since 2013. This retrospective study, throughout 2016, was conducted in the Central Laboratory of Chemical Biochemistry at the University Hospital Ramón y Cajal. All blood tests with serum albumin, total cholesterol, and total lymphocyte count were studied. The degree of malnutrition was assessed using the scale of normal $(=0)$, mild $(=4)$, moderate $(=8)$, and severe $(=12)$.

Results: In 2016, there were 405406 analytics performed in the laboratory of University Hospital Ramón y Cajal. The CONUT tool was applied to $3.64 \%$ of them (14741 analytics). In the outpatient setting, the highest malnutrition index comprised patients from the liver transplant consultation department, followed by the cardiology, rheumatology, and oncology departments. With inpatients, the hematology, cardiology, and endocrinology departments showed the most severe malnutrition index.

Conclusion: The CONUT system seemed to provide useful information about the cohort of the studied hospital. The results showed that $94 \%$ of the patients were not classified with malnutrition, there was no gender predilection, and they were younger than the rest. Patients with more severe malnutrition were usually older and male.

Keywords: Malnutrition, Early Diagnosis, Laboratories, Nutritional Status
\end{abstract}

\section{Background}

Hospital malnutrition occurs mainly because of the effects of disease and its treatment. It is a highly prevalent healthcare problem associated with high costs, but it is still undervalued. ${ }^{1}$

In Spain, the prevalence of malnutrition in hospitalized patients has been reported to range from $30 \%$ to $50 \%{ }^{1,2}$ According to the Spanish National Institute of Statistics, ${ }^{3}$ about 2 million out of 4.7 million patients discharged from Spanish public hospitals were in a malnourished condition caused by factors related to disease, many therapeutic procedures (surgery, radio, chemotherapy, transplants, etc) used to treat disease, and other aspects of hospitalization. ${ }^{3}$

Nutritional risk has been demonstrated to be an independent predictor of functional status and mortality in institutionalized elderly patients. ${ }^{4}$ This endemic situation can be described as "clinical malnutrition". Frequently, it has begun before hospitalization and usually persists after hospital discharge.

The most frequently used indexes to clinically evaluate the nutritional status of patients at the studied hospital were body mass index (BMI), serum albumin levels, and prealbumin levels. ${ }^{5}$ However, these single items demonstrated limited clinical applications. Thus, more complete and improved nutritional indexes were developed. Among the most commonly used nutritional indicators in elderly patients are the Geriatric Nutritional Risk Index (GNRI) ${ }^{6,7}$ and the Controlling Nutritional Status (CONUT) score..$^{3,8-11}$

It is crucial to use a nutritional alert system, such as the CONUT (COntrol NUTrition) program, as an alert to possible malnutrition in a patient. This program is based on 3 analytical parameters: serum albumin concentration,

Copyright (C) 2018 The Author(s). This is an open-access article distributed under the terms of the Creative Commons Attribution License (http:// creativecommons.org/licenses/by/4.0), which permits unrestricted use, distribution, and reproduction in any medium, provided the original work is properly cited. 
total cholesterol level, and total peripheral lymphocyte count as indicators of protein reserves, caloric depletion, and impaired immune defenses, respectively. Depending on the level of each parameter, a score is assigned which indicates the nutritional status of the patient. ${ }^{3,8,9}$

The Clinical Biochemistry Department at the University Hospital Ramón y Cajal has a centralized laboratory which performs all biochemistry samples in the northeast area of Madrid. All samples from inpatients and ambulatory patients were analyzed. Outpatients came from either the twenty primary care health centers or the 2 specialty care health centers. Samples were from either routine or urgent testing. The laboratory is also a reference laboratory for special techniques, from both other areas of Madrid and other autonomous regions, and works 24 hours a day, 7 days a week.

The cohort of this study comprised 573,654 inhabitants registered in the Northeast Sanitary Area of Madrid (formerly the 4 th Area), Spain. ${ }^{12}$

\section{Objective}

The main objective of the current study was to evaluate the experience of the implementation of the CONUT program in the computer system of the central laboratory at the University Hospital Ramón y Cajal.

An attempt was also made to determine the following:

- Malnourished patients or those at risk of malnutrition through basic analysis that should be requested for every sick person, especially those to be admitted to a hospital or assisted-living residence.

- The risk of malnutrition using recorded data (age, diagnosis, therapeutic procedure, length of stay).

- The degree of risk and evolution of the degree of malnutrition in each patient.

- The risk of changes in nutritional status based on diagnosis, hospital stay, and proposed new therapeutic procedures.

Attempts were also made to

- Correlate patient malnutrition and its risks with probable causes, known or unknown.

- Provide early intervention through the appropriate nutritional support and the monitoring of results.

\section{Methods}

\subsection{Study Design}

This was a retrospective, descriptive study.

\subsection{Inclusion Criteria}

All blood samples taken in 2016 that fulfilled the following criteria were included in the study:

- Determination of serum albumin (bromocresol purple method -BCP-), measured in the ARCHITECT c16000 (Abbott);

- Totalcholesterol(enzymaticmethod ofthe combination of hydrogen peroxide with hydroxybenzoic acid and 4-aminoantipirin), measured in the ARCHITECT c16000 (Abbott);
- Total lymphocytes, measured in a Sapphire Cell Dyn (Abbott) cell analyzer.

\subsection{Exclusion Criterion}

Any sample not meeting the inclusion criteria was excluded.

\subsection{Patients}

Blood samples sent to the laboratory from all hospitalized and outpatient subjects upon hospitalization and at the time of discharge were examined.

The malnutrition scores and the evaluation of the nutritional alert are summarized in Table 1.

\subsection{Program Used:}

The Nutrition Unit of the University Hospital La Princesa, Madrid (Spain) developed the new software application for CONUT. It was conceived for use in public hospitals. This basic program allows the linking of admission and laboratory databases in order to extract some clinical indicators. Previously, an appropriate weight was assigned to each factor. The program takes into consideration a patient's specific nutritional care, including notification of a "Nutritional Alert" to the responsible (requesting) department in situations of nutritional risk. The importance ratings initially assigned to these variables were those determined in previous studies and recently validated by logistic regression and ROC curve analysis.

The program processes the data in seconds and automatically informs about:

- The degree of malnutrition presented by all analyzed patients throughout each day;

- The evolution of analytical data prior to the patient's admission, in the hospital, and as an out-patient consultation as well as changes in the degree of a patient's malnutrition and risk.

The time required for data collection, processing, and application is less than 5 minutes.

The CONUT score has been used in the computerized system of the University Hospital Ramón y Cajal central laboratory since 2013. Patients with CONUT scores of 0-1 have a normal nutritional status, those with CONUT scores of 2-4 are at mild risk, those with CONUT scores of

Table 1. Malnutrition Score and Evaluation of Nutritional Alert (CONUT, Adults)

\begin{tabular}{lcccc}
\hline Parameter & Normal & Mild & Moderate & Severe \\
\hline Albumin & $\geq 3.50$ & $3.00-3.49$ & $2.50-2.99$ & $<2.50$ \\
Range & $(0)$ & $(1)$ & $(2)$ & $(3)$ \\
Total lymphocytes & $\geq 1600$ & $1200-1599$ & $800-1199$ & $<800$ \\
Range & $(0)$ & $(1)$ & $(2)$ & $(3)$ \\
Total cholesterol & $\geq 180$ & $140-179$ & $100-139$ & $<100$ \\
Range & $(0)$ & $(1)$ & $(2)$ & $(3)$ \\
$\begin{array}{l}\text { Total range } \\
\text { (CONUT score) }\end{array}$ & $(0-1)$ & $(2-4)$ & $(5-8)$ & $(9-12)$ \\
$\begin{array}{l}\text { Alert of } \\
\text { malnutrition }\end{array}$ & Low alert & Low alert & Moderate & alert \\
\hline
\end{tabular}


5-8 are at moderate risk, and those with CONUT scores of 9-12 are at severe risk of malnutrition.

\subsection{Statistical Analyses}

The quantitative analytical variables are expressed as mean plus standard deviation. The qualitative variables are expressed as percentages. The chi-square test was used to evaluate the associations among the different variables. All calculations were made using the statistical package STATA version 11 (Stata Corp. College Station, Texas, USA).

\section{Results}

In 2016, a total of 405406 analytics were performed, and the CONUT program was applied to $3.64 \%$ of them (14 741 analytics). The monthly distribution had no significant differences. Of the total, $50.3 \%$ belonged to men with a mean age of 56.8 years, and the rest were from women with a mean age of 60.4 years.

The results of all malnutrition degrees according to the number of analytics performed, gender, and mean age are summarized in Table 2.

The 4 levels of malnutrition degree related to patient's mean age, gender, and percentage are summarized in Table 3.

No date of birth was noted in 125 cases, and those cases were excluded from the study.
Data regarding the department originally requesting the analytics is shown in Table 4 . It can be seen that a great majority of the samples were requested by the hospital's outpatient clinic, followed by primary care patients and admitted patients.

The results showed that the outpatient departments requested albumin, cholesterol, and lymphocytes tests most often. The distribution is summarized in Table 5 .

The greatest number of requests was made by the departments of kidney and liver transplant outpatient consultations and consultations from patients with hepatic, renal, and hematology diseases. Furthermore, the department of liver transplant consultation had the highest malnutrition index.

In admitted patients, this distribution is different (Table 6). Patients admitted to the hematology department had the most severe degree of malnutrition ( mean $=6.8$ ), mainly due to more frequent lymphopenia compared with other departments. Patients admitted to the cardiology department also had a severe degree of malnutrition (mean = 5.4); moreover, they were older than patients from other departments. On the other hand, patients admitted to the endocrinology department were the youngest (excluding pediatrics) and had a high degree of malnutrition (mean $=4.0$ ). Nevertheless, this degree was lower than that of patients admitted to cardiology.

Table 2. Malnutrition Degrees, Number of Analytics, Gender, and Mean Age

\begin{tabular}{|c|c|c|c|c|c|c|c|c|c|c|}
\hline $\begin{array}{l}\text { Malnutrition } \\
\text { Degree }\end{array}$ & $\begin{array}{c}\text { No. of } \\
\text { Analytics }\end{array}$ & $\begin{array}{l}\% \text { of Total } \\
\text { Analytics }\end{array}$ & Male & $\begin{array}{c}\% \text { Male of } \\
\text { Total Patients }\end{array}$ & $\begin{array}{l}\% \text { Male of } \\
\text { Total Males }\end{array}$ & Female & $\begin{array}{l}\% \text { Female of } \\
\text { Total Patients }\end{array}$ & $\begin{array}{l}\% \text { Female of } \\
\text { Total Females }\end{array}$ & $\begin{array}{c}\text { Mean } \\
\text { Age }(y)\end{array}$ & SD (y) \\
\hline 0 Normal & 4724 & $32.0 \%$ & 2321 & $15.7 \%$ & $29.4 \%$ & 2403 & $16.3 \%$ & $35.2 \%$ & 58.4 & 16.7 \\
\hline 1 Normal & 3462 & $23.5 \%$ & 1986 & $13.5 \%$ & $25.1 \%$ & 1476 & $10.0 \%$ & $21.6 \%$ & 57.1 & 20.5 \\
\hline 2 Mild & 2252 & $15.3 \%$ & 1226 & $8.3 \%$ & $15.5 \%$ & 1026 & $7.0 \%$ & $15.0 \%$ & 60.4 & 21.2 \\
\hline 3 Mild & 1359 & $9.2 \%$ & 727 & $4.9 \%$ & $9.2 \%$ & 632 & $4.3 \%$ & $9.2 \%$ & 67 & 18.2 \\
\hline 4 Mild & 753 & $5.1 \%$ & 404 & $2.7 \%$ & $5.1 \%$ & 349 & $2.4 \%$ & $5.1 \%$ & 68 & 19 \\
\hline 5 Moderate & 623 & $4.2 \%$ & 326 & $2.2 \%$ & $4.1 \%$ & 297 & $2.0 \%$ & $4.3 \%$ & 71.8 & 18.2 \\
\hline 6 Moderate & 463 & $3.1 \%$ & 261 & $1.8 \%$ & $3.3 \%$ & 202 & $1.4 \%$ & $3.0 \%$ & 67.1 & 20.7 \\
\hline 7 Moderate & 392 & $2.7 \%$ & 221 & $1.5 \%$ & $2.8 \%$ & 171 & $1.2 \%$ & $2.5 \%$ & 69.6 & 17.3 \\
\hline 8 Moderate & 251 & $1.7 \%$ & 142 & $1.0 \%$ & $1.8 \%$ & 109 & $0.7 \%$ & $1.6 \%$ & 69.3 & 17.5 \\
\hline 9 Severe & 204 & $1.4 \%$ & 132 & $0.9 \%$ & $1.7 \%$ & 72 & $0.5 \%$ & $1.1 \%$ & 68.6 & 16.9 \\
\hline 10 Severe & 129 & $0.9 \%$ & 77 & $0.5 \%$ & $1.0 \%$ & 52 & $0.4 \%$ & $0.8 \%$ & 67.8 & 16.4 \\
\hline 11 Severe & 98 & $0.7 \%$ & 60 & $0.4 \%$ & $0.8 \%$ & 38 & $0.3 \%$ & $0.6 \%$ & 65 & 17.9 \\
\hline 12 Severe & 31 & $0.2 \%$ & 25 & $0.2 \%$ & $0.3 \%$ & 6 & $0.0 \%$ & $0.1 \%$ & 62.4 & 19 \\
\hline Total (\%) & 14741 & $100.0 \%$ & $\begin{array}{c}7908 \\
(53.6 \%)\end{array}$ & & & $\begin{array}{c}6833 \\
(46.4 \%)\end{array}$ & & & 64.5 & 19.4 \\
\hline
\end{tabular}

Table 3. Punctuation of Malnutrition, Mean Age, and Gender, With Percentages

\begin{tabular}{|c|c|c|c|c|c|c|c|c|c|c|}
\hline $\begin{array}{l}\text { Malnutrition } \\
\text { Degree }\end{array}$ & $\mathbf{N}$ & $\begin{array}{c}\text { Total Mean } \\
\text { Age } \pm \text { SD }(y)\end{array}$ & $\begin{array}{l}\text { No. of } \\
\text { Males }\end{array}$ & $\begin{array}{l}\% \text { Males of } \\
\text { Total Males }\end{array}$ & $\begin{array}{l}\% \text { Males of } \\
\text { Total Patients }\end{array}$ & $\begin{array}{c}\text { Male Mean } \\
\text { Age } \pm \text { SD (y) }\end{array}$ & $\begin{array}{l}\text { No. of } \\
\text { Females }\end{array}$ & $\begin{array}{l}\% \text { Females of } \\
\text { Total Females }\end{array}$ & $\begin{array}{l}\% \text { Females of } \\
\text { Total Patients }\end{array}$ & $\begin{array}{c}\text { Female Mean } \\
\text { Age } \pm S D(y)\end{array}$ \\
\hline Normal & 8117 & $58.4 \pm 8.4$ & 4280 & $54.43 \%$ & $29.3 \%$ & $57.2 \pm 17.3$ & 3837 & $56.8 \%$ & $26.3 \%$ & $59.8 \pm 19.5$ \\
\hline Mild & 4337 & $64.3 \pm 20.2$ & 2347 & $29.84 \%$ & $16.1 \%$ & $63.2 \pm 19.1$ & 1990 & $29.5 \%$ & $13.6 \%$ & $65.7 \pm 21.4$ \\
\hline Moderate & 1702 & $70.2 \pm 18.7$ & 945 & $12.0 \%$ & $6.5 \%$ & $68.1 \pm 17.0$ & 757 & $11.2 \%$ & $5.2 \%$ & $72.9 \pm 20.3$ \\
\hline Severe & 460 & $67.7 \pm 17.2$ & 292 & $3.7 \%$ & $2.0 \%$ & $66.8 \pm 16.7$ & 168 & $2.5 \%$ & $1.1 \%$ & $69.4 \pm 17.9$ \\
\hline
\end{tabular}


Table 4. Analytics According to Origin

\begin{tabular}{lc}
\hline Emergency Department & $42(0.3 \%)$ \\
Hospital outpatient clinics (OPC) & $8459(57.4 \%)$ \\
Secondary care (non-hospital OPC) & $1185(8.0 \%)$ \\
Hospitalized & $2104(14.3 \%)$ \\
Others & $66(0.4 \%)$ \\
Primary care & $2873(19.5 \%)$ \\
(Not specified) & $12(0.1 \%)$ \\
\hline
\end{tabular}

Table 5. Outpatient departments that most frequently requested tests of albumin, cholesterol, and lymphocytes

\begin{tabular}{lcccc}
\hline Department & N & $\begin{array}{c}\text { \% (From } \\
\text { Total) }\end{array}$ & $\begin{array}{c}\text { CONUT } \\
\text { (Mean) }\end{array}$ & $\begin{array}{c}\text { Age } \\
\text { (Mean) }\end{array}$ \\
\hline Cardiology & 75 & $0.8 \%$ & 2.6 & 60.7 \\
Surgery & 64 & $0.7 \%$ & 2.1 & 63.3 \\
Endocrinology & 341 & $3.5 \%$ & 1.2 & 47.2 \\
Gastroenterology & 1741 & $18.1 \%$ & 1.5 & 58.3 \\
Hematology & 1267 & $13.1 \%$ & 2.1 & 63.5 \\
Infectious Diseases & 765 & $7.9 \%$ & 1.1 & 50.3 \\
Internal Medicine & 682 & $7.1 \%$ & 2.0 & 74.1 \\
Nephrology & 1313 & $13.6 \%$ & 1.7 & 65.0 \\
Oncology & 672 & $7.0 \%$ & 2.2 & 67.0 \\
Pediatrics & 103 & $1,1 \%$ & 2.0 & 21.8 \\
Rheumatology & 85 & $0.9 \%$ & 2.5 & 60.1 \\
Hepatic Transplant & 627 & $6.5 \%$ & 3.1 & 59.3 \\
Renal Transplant & 1467 & $15.2 \%$ & 1.6 & 60.2 \\
\hline Others: Immunology, & 442 & $4.6 \%$ & 1.6 & 61.4 \\
Gynecology, etc. & & $100 \%$ & 1.8 & 60.8 \\
\hline Total & 9644 & & & \\
\hline
\end{tabular}

Table 6. Inpatient departments that most frequently requested albumin, cholesterol, and lymphocytes

\begin{tabular}{lcccc}
\hline Department & N & $\begin{array}{c}\text { \% (From } \\
\text { Total) }\end{array}$ & $\begin{array}{c}\text { CONUT } \\
\text { (Mean) }\end{array}$ & $\begin{array}{c}\text { Age } \\
\text { (Mean) }\end{array}$ \\
\hline Cardiology & 17 & $0.8 \%$ & 5.4 & 73.3 \\
Surgery & 25 & $1.2 \%$ & 1.4 & 67.3 \\
Endocrinology & 8 & $0.4 \%$ & 4.0 & 49.7 \\
Gastroenterology & 309 & $14.7 \%$ & 2.7 & 59.4 \\
Hematology & 335 & $15.9 \%$ & 6.8 & 56.2 \\
Infectious & 509 & $24.2 \%$ & 1.4 & 51.6 \\
Internal Medicine & 221 & $10.5 \%$ & 2.9 & 63.3 \\
Nephrology & 500 & $23.8 \%$ & 3.9 & 64.9 \\
Oncology & 43 & $2.0 \%$ & 3.2 & 66.9 \\
Pediatrics & 39 & $1.9 \%$ & 1.7 & 15.1 \\
Others & 98 & $4.7 \%$ & 2.4 & 62.2 \\
\hline Total & 2104 & $100 \%$ & 3.3 & 58.3 \\
\hline
\end{tabular}

\section{Discussion}

Disease-related malnutrition is a prevalent healthcare problem in Spain. ${ }^{1}$ The University Hospital Ramón y Cajal is one of the largest tertiary hospitals in Spain. It has all services except maternity, including an organ transplant surgery unit and a gender identity unit.

As explained above, the CONUT program is an automated system for monitoring clinical risk, quantifying initial undernutrition, and monitoring recovery after adequate treatment. ${ }^{4}$

The results of the current study indicate that patients with a normal nutritional status were younger than those with some degree of malnutrition (mild, moderate, or severe). It was also observed that there were more male patients with higher levels of malnutrition than females; the number of male patients with severe malnutrition was almost double (294 cases) that of females (168 cases) with the same degree of malnutrition.

In the current study, the CONUT system seemed to provide useful information. The results showed that $94.2 \%$ of the patients did not have malnutrition, and the cohort had an equitable distribution by gender, but ages clearly younger than the rest.

The greatest number of samples were from outpatients about six times more than inpatients. This may explain why $94.2 \%$ of patients in this study did not have malnutrition. The distribution by gender in this group was equitable, but the patients' ages were inferior to the rest.

As in other studies, ${ }^{13}$ patients with moderate and severe malnutrition had a higher mean age in this study, and within this group there was a greater proportion of males; nevertheless, they were younger than the females.

\section{Conclusion}

The CONUT system is a useful automatized method for use in the nutritional screening of patients, regardless of whether they are inpatients or outpatients or attended in primary or specialized care units. CONUT adds a benefit to the information provided by the clinical laboratory. It provides information about patients for whom correcting their state of malnutrition should be emphasized and the services that attend patients with greater risk.

In this cohort, $94.2 \%$ of the patients did not present malnutrition; these patients had an equitable distribution by sex, but their ages were clearly inferior to the rest.

Patients with moderate and severe malnutrition had a higher mean age. Within this group, there was a greater proportion of males, and the males were younger than the females.

\section{Authors' Contributions}

All authors contributed equally to this study.

\section{Conflict of Interest Disclosures}

None of the authors nor their families have received or will receive any benefits or economic compensation from the completion of this study.

\section{Ethical Approval}

Because this study is retrospective, observational, noninterventionist in nature, and anonymous, obtaining the patients' informed consent was not necessary. The study followed the Declaration of Helsinki principles and its subsequent versions. 


\section{Research Highlights}

\section{What Is Already Known?}

The CONUT (COntrol NUTrition) program is an automatized method for the nutritional screening of patients at the University Hospital Ramón y Cajal. It provides information about patients for whom correcting their state of malnutrition should be emphasized in addition to information on the services that attend patients with greater risk. This tool uses 3 analytical parameters: serum albumin, total cholesterol, and total lymphocytes.

\section{What This Study Adds?}

The current study confirmed that the CONUT program is useful in diagnosing patients with malnutrition. In this cohort, $94.2 \%$ of the patients did not present with malnutrition; there was an equitable distribution by gender in this group, and their ages were clearly inferior to the other patients.

Patients with moderate and severe malnutrition had a higher mean age. Within this group, there was a greater proportion of males, but they were younger than the females.

No further requests were added to the original orders of the requesting physicians. No analysis was performed other than the original requests made by the physicians.

\section{Acknowledgments}

The authors are indebted to Dr. Joseph Hogg, partner at the Abbey House Medical Centre, for his careful English revision.

\section{References}

1. García de Lorenzo A, Álvarez Hernández J, Planas M, et al. Multidisciplinary consensus work-team on the approach to hospital malnutrition in Spain. Nutr Hosp. 2011;26(4):701710. doi:10.1590/S0212-16112011000400006.

2. Moriana M, Civera M, Artero A, et al. Validez de la valoración subjetiva global como método de despistaje de desnutrición hospitalaria. Prevalencia de desnutrición en un hospital terciario (Validity of subjective global assessment as a screening method for hospital malnutrition. Prevalence of malnutrition in a tertiary hospital). Endocrinol Nutr. 2014;61:184-189. doi:10.1016/j.endonu.2013.10.006.

3. Ulíbarri Pérez JI, Fernández G, Rodríguez Salvanés F, et al.
Proyecto para la Prevención, Detección precoz y Control de la Desnutrición Clínica. (Proyecto CONUT). Actualizado en Octubre 2013. Project for the Prevention, Early detection and Control of Clinical Malnutrition (The CONUT project). https:// controlnutricional.files.wordpress.com/2010/12/proyectoconut-octubre-2013.pdf. Accessed May 11, 2018. Updated October 2013.

4. Cereda E, Pedrolli C, Zagami A, et al. Nutritional risk, functional status and mortality in newly institutionalised elderly. Br J Nutr. 2013;110:1903-1909. doi:10.1017/S0007114513001062.

5. Alcorta MD, Alvarez PC, Cabetas RN, et al. The importance of serum albumin determination method to classify patients based on nutritional status. Clin Nutr ESPEN. 2018;25:110113. doi:10.1016/j.clnesp.2018.03.124.

6. Xie $\mathrm{Y}$, Zhang $\mathrm{H}$, Ye $\mathrm{T}$, et al. The geriatric nutritional risk index independently predicts mortality in diabetic foot ulcers patients undergoing amputations. J Diabetes Res. 2017;2017: 5797194. doi:10.1155/2017/5797194.

7. Takahashi S, Suzuki K, Kojima F, et al. Geriatric nutritional risk index as a simple predictor of mortality in maintenance hemodialysis patients: a single center study. Int J Clin Med. 2015;6:354-362. doi:10.4236/ijcm.2015.65046.

8. Sun $X$, Luo L, Zhao $X$, et al. Controlling Nutritional Status (CONUT) score as a predictor of all-cause mortality in elderly hypertensive patients: a prospective follow-up study. BMJ Open. 2017;7:e015649. doi:10.1136/bmjopen-2016-015649.

9. Ulíbarri Pérez JI, Fernández G, Rodríguez Salvanés F, et al. Nutritional screening; control of clinical undernutrition with analytical parameters. Nutr Hosp. 2014;29(4):797-811. doi:10.3305/nh.2014.29.4.7275.

10. Molina Soria JB, Lobo Támer G, Pérez de la Cruz AJ, et al. Prevalencia de desnutrición al ingreso en un hospital general básico (Prevalence of malnutrition to income in a basic general hospital). Nutr Hosp 2017;34(6):1390-1398. doi:10.20960/ nh.1133.

11. Rentero Redondo L, Iniesta Navalón C, Gascón Cánovas $\mathrm{J}$, et al. Desnutrición en el paciente anciano al ingreso hospitalario, un viejo problema sin solucionar (Malnutrition in the elderly patient to hospital admission, an old problem unsolved). Nutr Hosp. 2015;1;32:2169-2177. doi:10.3305/ nh.2015.32.5.9712.

12. Secretaría General del Servicio Madrileño de Salud. Comunidad de Madrid. Hospital Universitario "Ramón y Cajal". Memoria 2016. Edición electrónica 9/2017. http://www.madrid.org/cs/ Satellite?blobcol=urldata\&blobheader=application $\% 2$ Fpdf\&bl obheadername $1=$ Contentdisposition \&blobheadername $2=\mathrm{cad}$ ena\&blobheadervalue $1=$ filename\%3DMemoria+2016.pdf\&bl obheadervalue $2=$ language $\% 3 \mathrm{Des} \% 26 \mathrm{site} \% 3 \mathrm{DH}$ ospitalRamo nCajal \&blobkey $=$ id \&blobtable $=$ MungoBlobs \&blobwhere $=13$ $52944025120 \&$ ssbinary $=$ true.

13. Abd Aziz NAS, Teng NIMF, Abdul Hamid MR, et al. Assessing the nutritional status of hospitalized elderly. Clin Interv Aging. 2017:12:1615-1625. doi:10.2147/CIA.S140859. 